\title{
Aplicação de Indicadores Ácido- Base na Determinação Espectrofotométrica de Amônia em Água por Análise em Fluxo
}

\section{Edmar I. Melo, Nívia M. M. Coelho \& Danilo A. Giarola}

O trabalho propõe o uso de indicadores ácido-base para detecção espectrofotométrica acoplada a análise por injeção em fluxo. O comportamento da banda de absorção da fenolftaleína em 552nm foi usado para monitorar o nitrogênio amoniacal total ( $\mathrm{N}_{-} \mathrm{NH}_{3}$ Total) e o comportamento da banda de absorção do púrpura de bromocresol, 440nm, foi proposto para detecção de espécies acidas. Amostras de água do rio Uberabinha (Uberlândia-MG) apresentaram índice de qualidade de água para ambientes aquáticos aceitáveis em 50\% dos pontos avaliados, considerando o parâmetro $\mathrm{N}^{-\mathrm{NH}_{3}}$ Total e os valores estabelecidos na resolução federal CONAMA 357.

Palavras-chave: indicador ácido-base, amônia, injeção em fluxo.

The work proposes the use of acid-base indicators for spectrophotometric detection coupled to flow injection analysis. The behavior of the absorption band of phenolphthalein at $552 \mathrm{~nm}$ was used to monitor the ammoniac nitrogen $\left(\mathrm{NH}_{3}-\mathrm{N}\right)$ and the behavior of the absorption band of bromocresol purple, $440 \mathrm{~nm}$, was proposed for detection of acidic species. Samples of water of the Uberabinha River in the city Uberlandia - MG showed index of water quality for aquatic environments acceptable in $50 \%$ of the points evaluated considering the parameter ammoniac nitrogen $\left(\mathrm{NH}_{3}-\mathrm{N}\right)$ and the values established in the CONAMA resolution 357.

Keywords: acid-base indicator, ammonia, flow injection. 


\section{Introdução}

A amônia apresenta-se em ambientes aquáticos na forma molecular, amônia, $\mathrm{NH}_{3}$, também conhecida como amônia não-ionizada, e na sua forma iônica, amônio, $\mathrm{NH}_{4}{ }^{+}$. Devido à importância da amônia não-ionizada, tornou-se uma convenção na literatura científica expressar a toxicidade da amônia em termos desse composto. Critérios e padrões de qualidade da água seguiram essa convenção ${ }^{1,2}$. Neste estudo o termo amônia é genérico, utilizado para referir-se às formas $\mathrm{NH}_{3}$ e $\mathrm{NH}_{4}^{+}$em água, indistintamente, sendo assim será adotada a seguinte terminologia: amônia ou amônia total $\left(\mathrm{NH}_{3}\right.$ e $\left.\mathrm{NH}_{4}^{+}\right)$.

A amônia pode estar presente naturalmente em águas superficiais ou subterrâneas, sendo que usualmente sua concentração é muito baixa devido à sua fácil adsorção em partículas do solo ou sofrer oxidação formando nitrito e nitrato. Entretanto, a ocorrência de concentrações elevadas pode ser resultante de fontes de poluição, como oriunda do uso ou fabricação de fertilizantes, da refrigeração industrial. Uma fonte comum de contaminação da água com $\mathrm{NH}_{3}$ é o esgoto doméstico in natura em áreas altamente povoadas ${ }^{3}$.

$\mathrm{O}$ aspecto ambiental mais conhecido da $\mathrm{NH}_{3}$ talvez seja como nutriente que juntamente com o fósforo, favorecem o fenômeno de eutrofização. Ela não representa uma substância de grande toxicidade para o ser humano, sendo inclusive adicionada à água potável para permitir um tempo de residência maior do cloro residual no sistema de distribuição ${ }^{4,5}$. Estudos têm mostrado que a presença de matéria orgânica e amônia são responsáveis em pela diminuição da qualidade destas águas, afetando o equilíbrio das comunidades aquáticas ${ }^{6,7}$.

A forma não-ionizada é muito mais tóxica que a iônica, certamente graças a sua capacidade de difusão através da membrana epitelial dos organismos aquáticos. Estudos mais recentes sobre a toxicidade crônica da amônia em ambientes aquáticos, publicados pela Environmental Protection Agency (EPA) $)^{1,2}$ são definidos em função do $\mathrm{pH}$ e da temperatura. A toxicidade da amônia adotada pela EPA foi incorporada pela Resolução Federal CONAMA 357, onde os valores máximos para águas de classe 1, 2 e 3 estão estabelecidos ${ }^{1,8}$.
Os métodos mais utilizados para a determinação de Ntotal são o de Kjeldahl, que é essencialmente um procedimento de oxidação úmida e o método de Dumas, que é basicamente uma técnica de oxidação seca (combustão) ${ }^{9,10}$. Estas técnicas são mais adequadas para amostras sólidas como solo, sedimentos, alimentos e comparáveis quando a concentração de nitrogênio é de aproximadamente $200 \mathrm{mg} \mathrm{kg}^{-1}$.

Entre os métodos espectrofotométricos mais sensíveis, está o método do indofenol que é utilizado principalmente para análise de águas. Este método se baseia na formação do composto azul de indofenol (reação de Berthelot), resultante da reação do íon amônio com um composto fenólico, na presença de um agente oxidante e de um catalisador ${ }^{11}$. É um método que apresenta altos desvios do branco, e na faixa de concentração micromolar, a precisão é raramente melhor que cerca de $10 \%{ }^{12}$.

A determinação de nitrogênio amoniacal em sistemas de análises em fluxo tem empregado principalmente potenciometria, espectrofotometria UV-Vis e condutimetria, envolvendo em geral difusão gasosa $^{13,14}$. Métodos espectrofotométricos diretos, por exemplo, o do azul de indofenol, acoplados em sistemas de análises em fluxo tem sido usados ${ }^{15,16}$. O acoplamento da análise de injeção em fluxo por difusão gasosa e detecção espectrofotométrica, proporciona um método de análise que apresenta sensibilidade, freqüência analítica alta, limite de detecção e limite de quantificação, compatíveis com os valores estabelecidos na legislação ${ }^{13}$.

O presente trabalho propõe o uso de dois indicadores ácido-base para detecção espectrofotométrica acoplada com analise por injeção em fluxo, onde a fenolftaleína foi usada para monitorar nitrogênio amoniacal total em água e o púpura de bromocresol foi proposto para monitorar espécies ácidas. Estes dois compostos são moléculas orgânicas cromóforas que absorvem na região do visível, cuja sensibilidade à concentração de íons $\mathrm{H}^{+}$permite indicar o grau de acidez do ambiente onde estão inseridos. Esta propriedade advém do fato deles próprios serem substâncias ácidas ou básicas fracas e que tem seu sistema cromóforo fortemente influenciado pelo grupamento ácido/básico, bem como podendo ser decorrente de modificações estruturais complexas ${ }^{17}$. 


\section{Parte Experimental}

\section{INSTRUMENTAÇÃO}

O sistema de fluxo empregado na determinação de amônia total está representado na figura 1 .

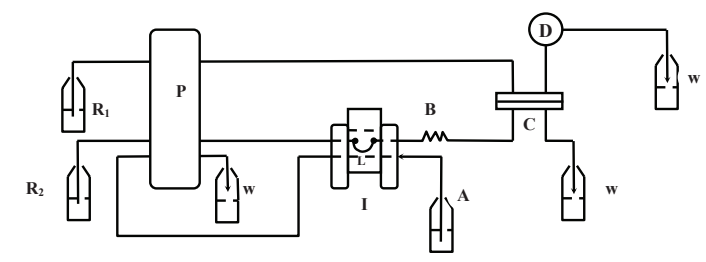

Figura 1. Sistema de fluxo proposto para determinação de amônia total. $\mathbf{R}_{1}$ : solução de indicador ácido-base, $\mathbf{R}_{2}$ : hidróxido de sódio 0,01 mol L ${ }^{-1}, \mathbf{P}$ : bomba peristáltica, $\mathbf{W}$ : descarte, $\mathbf{L}$ : alça de amostragem de $250 \mu \mathrm{L}$, I: injetor comutador, A: amostra ou soluções padrões, B: bobina de reação de 25,0 cm, C: unidade de difusão gasosa, $\mathbf{D}$ : detector espectrofotométrico. Vazão: 3,6 mL/min.

As soluções são impulsionadas por uma bomba peristáltica Gilson, modelo Minipuls 3 com 8 canais, utilizando tubos de tygon ${ }^{\circledR}$ para bombeamento. Tubos de polipropileno de 1,0mm de diâmetro são usados para construção do sistema de fluxo. A unidade de comutação para a introdução das amostras e padrões é um injetor comutador circular ${ }^{18,19}$. Os espectros eletrônicos das soluções aquosas dos indicadores, foram obtidos em um Espectrofotômetro HACH DR-4000U. As leituras de absorbância no sistema em fluxo foram realizadas com Espectrofotômetro Femto modelo 600S Plus. Para separação da amônia foi utilizada uma unidade de difusão gasosa com membrana de teflon ${ }^{\circledR 20}$.

\section{REAGENTE}

Todos os reagentes utilizados neste trabalho são de grau analítico e foram empregados sem purificação prévia. Foi preparada uma solução estoque de sulfato de amônio (Merck) de $100 \mathrm{mg} \mathrm{L}^{-1}$ usada no preparo das soluções padrões de 2, 4, 5, 10, 15, 20, $25 \mathrm{mg} \mathrm{L}^{-1}$. Solução de fenolftaléina (Synth) 1,6 x 10 $0^{-2} \mathrm{~mol} \mathrm{~L}^{-1} \mathrm{e}$ solução de púpura e de bromocresol (3',5"- Dibromo-oCresolsulfonoftaleína, Synth) 1 x 10-3 mol L-1. Solução de hidróxido de sódio (Merck) 0,1 mol L-1. Os demais compostos utilizados nas soluções foram: o fosfato de sódio dibásico heptahidratado (Cinética), ácido cítrico anidro (Isofar).

\section{AMOSTRAS}

As amostras de água foram coletadas em frasco de polietileno, e acidificadas com solução de ácido sulfúrico $10 \%$ até pH 2,0. Foram acondicionadas sobre refrigeração numa temperatura de $4^{\circ} \mathrm{C}$ até realização das análises, num prazo máximo de sete dias.

As amostras de água foram coletadas da bacia hidrográficas do rio Uberabinha no município de Uberlândia-MG (figura 2)
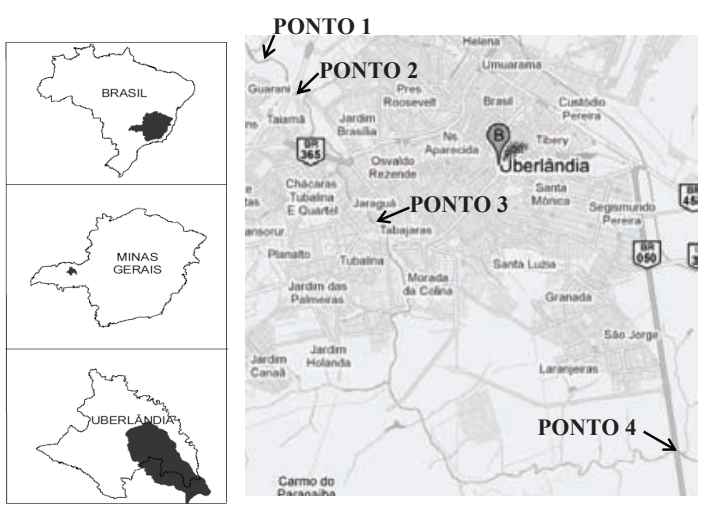

Figura 2. Mapa do município de Uberlândia com destaque para os pontos de coleta de amostra ao longo do Rio Uberabinha.

O ponto 4 se localiza sob a Br-050 (rodovia que liga o município às cidades de Uberaba-MG e Riberão Preto$\mathrm{SP})$. Este ponto encontra-se após a estação de tratamento e abastecimento de água do Sucupira e antes da área urbana, portanto sem recebimento de esgoto doméstico. O ponto 3 está localizado próximo ao centro da cidade, sob a ponte da avenida Getúlio Vargas. O ponto 2 está localizado sob o Anel Viário Ayrton Senna, próximo ao distrito Industrial. O ponto 1 está localizado na zona rural da cidade, após ter recebido a carga de efluentes domésticos, industriais e águas pluviais dos bairros próximos ao seu leito.

\section{Resultados e discussão}

Um indicador é um par conjugado de ácido e base de Brønsted-Lowry cujo ácido apresenta uma coloração e a base outra, ou seja, apresentam bandas de absorção em comprimentos de onda diferentes na região UV - Visível. Algumas vezes uma das duas espécies é incolor, não absorve nesta região do espectro eletromagnético ${ }^{21,22,23}$. A conversão entre as duas espécies, pode ser representada 
pelos equilíbrios da figura 3 (Púrpura de Bromocresol) e figura 4 (fenolftaleína).<smiles>Cc1cc(C2CCCCC2C(OS(=O)(=O)O)c2cc(C)c(O)c(Br)c2)cc(Br)c1O</smiles>

Purpura de bromocresol em meio ácido (amarelo)

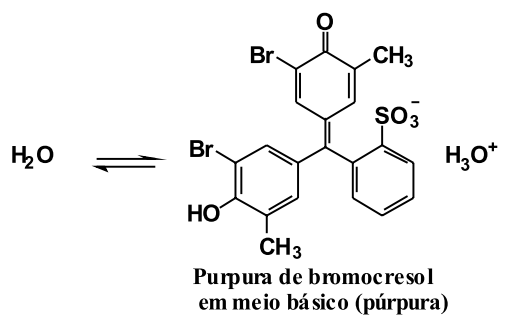

Figura 3. Equilíbrio ácido-base do indicador púrpura de bromocresol

O espectro de absorção para o púrpura de bromocresol obtido em $\mathrm{pH}$ 8,70 descrito na figura 5-f, apresenta uma banda em $590 \mathrm{~nm}\left(\varepsilon \sim 2,1 \times 10^{6} \mathrm{~mol}^{-1} \mathrm{~L} \mathrm{~cm}^{-1}\right)$, atribuída a transições $\pi-\pi^{*}$ da espécie aniônica (púrpura). A medida que o $\mathrm{pH}$ diminui essa banda desaparece e surge uma banda em 440nm $\left(\varepsilon \sim 0,7 \times 10^{6} \mathrm{~mol}^{-1} \mathrm{~L} \mathrm{~cm}^{-1}\right)$ associada à formação da espécie neutra (amarela). A presença de um ponto isosbéstico em $446 \mathrm{~nm}$ confirma a existência de um equilíbrio simples conforme proposto na figura $3^{24}$.

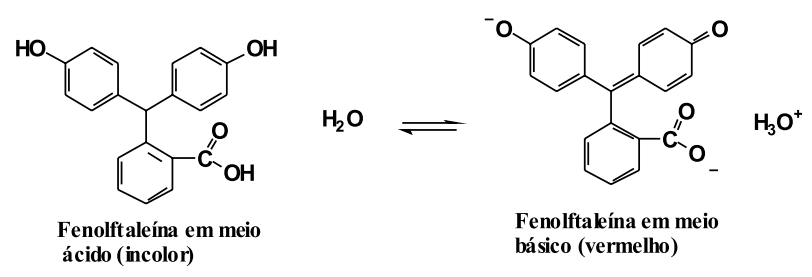

Figura 4. Equilíbrio ácido-base do indicador fenolftaleína

O comportamento da banda em $440 \mathrm{~nm}$ do púrpura de bromocresol, observado na figura 6 , pode ser usado como proposta de detecção acoplada ao sistema de fluxo descrito na figura 1. A intensidade de absorção de luz a 440nm responde linearmente a variação de $\mathrm{pH}$ do meio, para valores de $\mathrm{pH}$ entre 4,5 a 7,5. Desta forma uma solução deste indicador com $\mathrm{pH}$ ajustado para aproximadamente 7,5 poderá ser usada para monitorar espécies ácidas que permeiam a membrana da unidade de difusão gasosa (figura 1). A espécie acida provoca o deslocamento do equilíbrio descrito na figura 3 no sentido de aumentar a concentração do indicador na forma neutra, causando um aumento na absorção, de forma proporcional à concentração da espécie ácida que permeia a membrana.

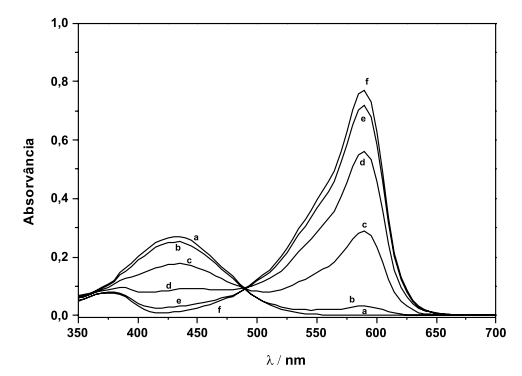

Figura 5. Espectro de absorção do indicador Púrpura de Bromocresol. [Indicador] = 1,0 x $10^{-4} \mathrm{~mol} \mathrm{~L}^{-1}$; $\mathrm{t}=28^{\circ} \mathrm{C}$; (a) $\mathrm{pH}=3,20$; (b) $\mathrm{pH}=4,70$; (c) $\mathrm{pH}=5,97$; (d) $\mathrm{pH}=6,66$; (e) $\mathrm{pH}=7,40$; (f) $\mathrm{pH}=8,70$.

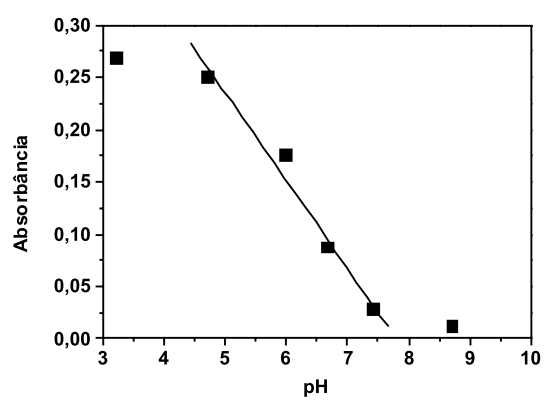

Figura 6. Intensidade de absorção do indicador púrpura de bromocresol a 440 nm em função do $\mathrm{pH}$

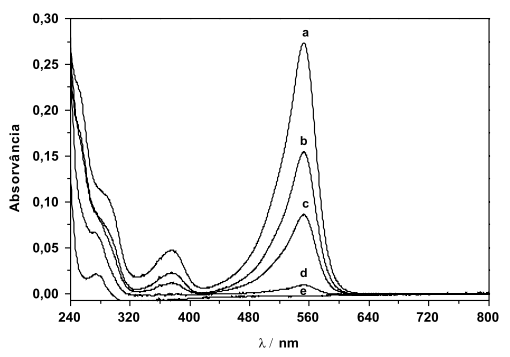

Figura 7. Espectro de absorção do indicador fenolftaleína. [Indicador]= $8,0 \times 10^{-4} \mathrm{~mol} \mathrm{~L}^{-1}$; $\mathrm{t}=29^{\circ} \mathrm{C}$; (a) $\mathrm{pH}=10,28$; (b) $\mathrm{pH}=9,93$; (c) $\mathrm{pH}=$ 9,61; (d) $\mathrm{pH}=8,83$; (e) $\mathrm{pH}=8,25$.

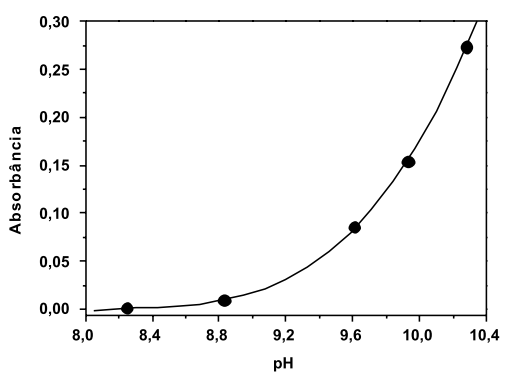

Figura 8. Intensidade de absorção do indicador fenolftaleína a 552 nm em função do $\mathrm{pH}$ 


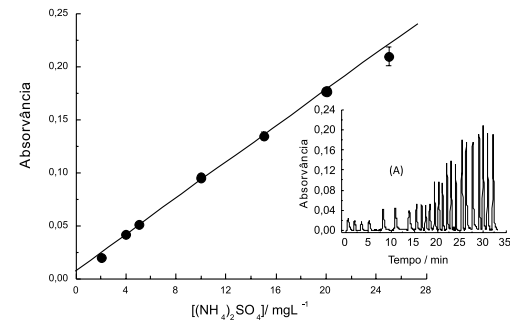

Figura 9. Curva analítica padrão .(A) Fiagrama referente às soluções padrões de sulfato de amônio (2, 4, 5, 10, 15, 20 e $\left.25 \mathrm{mg} \mathrm{L}^{-1}\right)$; Detecção a $552 \mathrm{~nm}$. Linearidade: Abs =0,00776 + 0,00853 [N-NH$\left.{ }_{3 T \text { total }}\right]$; coeficiente de correlação $=0,99336$.

$\mathrm{O}$ espectro de absorção para fenolftaleína em $\mathrm{pH}$ 10,28 descrito na figura 7, apresenta uma banda em 552 $\mathrm{nm}\left(\varepsilon \sim 2,7 \times 10^{4} \mathrm{~mol}^{-1} \mathrm{~L} \mathrm{~cm}^{-1}\right)$, atribuída a transições $\pi-\pi^{*}$ da espécie aniônica(vermelho) e outra banda de menor intensidade em $375 \mathrm{~nm}\left(\varepsilon \sim 0,5 \times 104 \mathrm{~mol}^{-1} \mathrm{~L} \mathrm{~cm}^{-}\right.$ $\left.{ }^{1}\right)$. A media que o $\mathrm{pH}$ vai aumentando a banda em 552 nm aumenta sua intensidade devido ao deslocamento do equilíbrio descrito na figura 4, no sentido de aumentar a concentração do indicador na forma aniônica.

Este comportamento da banda em $552 \mathrm{~nm}$ foi usado como proposta de detecção acoplada ao sistema de fluxo descrito na figura 1. Observa-se pela figura 8 uma baixa sensibilidade entre $\mathrm{pH}$ 8,0 e 9,4 e uma alta sensibilidade entre $\mathrm{pH}$ 9,5 e a 10,4. Desta forma uma solução deste indicador com pH ajustado entre 8,0 e 10,5 poderá ser usada para monitorar espécies alcalinas que permeiam a membrana da unidade de difusão gasosa (figura 1). A espécie básica provoca o deslocamento do equilíbrio descrito na figura 4 no sentido de aumentar a concentração do indicador na forma aniônica. O aumento da absorção em 552 nm é proporcional à concentração da espécie alcalina que permeou na membrana. Para a determinação de amônia, foi construído curva analítica padrão usando soluções padrões de sulfato de amônio (figura 9). Usando uma solução de fenolftaleína de $8,0 \times 10^{-4} \mathrm{~mol} \mathrm{~L}^{-1}$ e pH igual a 9,6, foi observado um coeficiente de correlação de 0,99336 confirmando uma correlação acima de 0,90 entre a resposta analítica e a concentração de nitrogênio

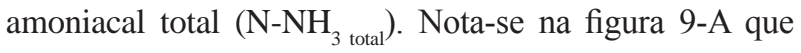
a linha base possui desvio padrão baixo. As variações inerentes ao método, podem ter sido causadas pela difusão de outros gases como, por exemplo, $\mathrm{CO}_{2}$, através da membrana, e sua inserção, com o passar do tempo, na solução de fenolftaleína, originado do ambiente. Esta oscilação na linha base não se mostrou uma barreira para a quantificação de amônia total. Observa-se que trabalhando com uma solução de fenolftaléina com pH ajustado para 9,6 obteve-se um limite de detecção de $0,2 \mathrm{mg} \mathrm{L}^{-1}$, limite de quantificação de $0,5 \mathrm{mg} \mathrm{L}^{-1}$, e uma sensibilidade de 0,00853 Abs/ $\mathrm{mgL}^{-1}$, enquanto que trabalhando com uma solução de fenolftaleína com um pH ajustado para 8,6 o limite de detecção e quantificação aumentaram para $1,3 \mathrm{mg} \mathrm{L}^{-1} \mathrm{e} 3,9$ mg $\mathrm{L}^{-1}$, respectivamente. A sensibilidade diminuiu para 0,0079 Abs/ $\mathrm{mgL}^{-1}$. Este aumento nos limites de detecção e quantificação e a diminuição na sensibilidade, estão em conformidade com o comportamento da fenolftaleína observados na figura 8, que para o valor de $\mathrm{pH}$ igual a 8,6 a resposta analítica não aumenta sensivelmente como em $\mathrm{pH}$ igual a 9,6.

Usando o módulo de análise descrito na figura 1 , e solução de fenolftaleína com pH igual a 9,6 foram analisadas amostras de água do rio Uberabinha, coletadas em quatro ponto (Figura 2) e os resultados da intensidade de absorção e concentração de nitrogênio amoniacal total são mostrados na figura 10 e tabela 1 , respectivamente.

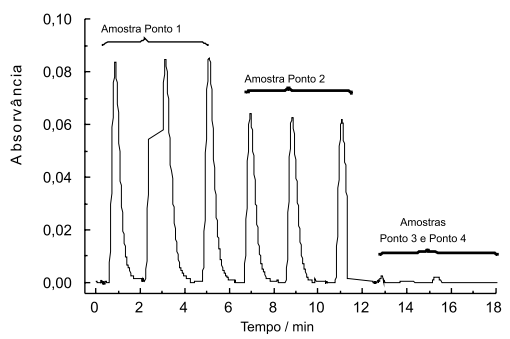

Figura 10. Fiagrama referente às amostras de água do rio Uberabinha

A portaria 518 de 25 de março de 2004, do Ministério da saúde, não coloca a NH3 entre as substâncias químicas que representam risco à saúde humana, mas dentro do contexto dos padrões de aceitação para consumo humano, ressalta seu efeito organoléptico. Desta maneira a portaria 518 estabeleceu o valor de $1,5 \mathrm{mg} \mathrm{L}^{-1}$ de NH3 total. Por outro lado a amônia ganha relevância quando se trata dos ecossistemas aquáticos, cujo objetivo é a proteção aos elementos da flora e fauna aquática.

A Resolução Federal CONAMA 357 estabelece que corpos hídricos classe 2, como do rio Uberabinha devem manter como uma de suas funções ecológicas o equilíbrio das comunidades aquáticas. Em seu artigo 34, 
parágrafo primeiro postula que "O efluente não deverá causar ou possuir potencial para causar efeito tóxico aos organismos aquáticos no corpo receptor...".

Tabela 1. Concentração de nitrogênio amoniacal total em amostras de água coletadas em diferentes pontos do rio Uberabinha no município de Uberlândia-MG.

\begin{tabular}{|c|c|}
\hline Ponto de Coleta & [NH3]/ mg L-1 \\
\hline P1 & $8,99 \pm 0,07$ \\
\hline P2 & $6,46 \pm 0,13$ \\
\hline P3 & $* * * *$ \\
\hline P4 & $* * * *$ \\
\hline \multirow{2}{*}{ **** valor menor que o LD do método. }
\end{tabular}

Este instrumento legal sustenta e abre caminho para um índice de qualidade das águas voltado para a proteção das comunidades aquáticas, pois além de explicitar a necessidade da manutenção da vida aquática, alerta para que este fato seja norteador do controle de fontes emissoras de poluentes.

Os resultados observados na tabela 1 , apresentam valores de $\mathrm{N}_{-} \mathrm{NH}_{3 \text { Total }}$ abaixo de $0,2 \mathrm{mg} \mathrm{L}^{-1}$ para os pontos 3 e 4 independentes do $\mathrm{pH}$ das amostras. Estes valores encontram-se abaixo do limite máximo estabelecido pela resolução 357, sendo assim estes pontos, segundo este parâmetro, são possuidores de um índice de qualidade de água aceitável para as comunidades aquáticas. No entanto o ponto 1 e 2 apresentaram valores de 8,99 e $6,46 \mathrm{mg} \mathrm{L}^{-1} \mathrm{~N}-\mathrm{NH}_{3 \text { Total }}$, repectivamente e um pH igual a 7,6, portanto acima do valor estabelecido pela resolução 357, não apresentando para este parâmetro um índice de qualidade de água para comunidades aquáticas aceitável.

\section{Conclusões}

O uso dos indicadores ácido-base para detecção espectrofotométrica acoplada com Análise de Injeção em Fluxo por difusão gasosa, apresentou sensibilidade, limite de detecção e limite de quantificação, compatíveis com os limites estabelecidos na legislação. O comportamento da banda de absorção em 552nm da fenolftaleína se mostrou eficiente para monitorar níveis de nitrogênio amoniacal total em água. De forma semelhante o comportamento da banda de absorção em 440nm do púrpura de bromocresol surge como proposta de detecção para espécies ácidas, acoplado a análise de injeção em fluxo por difusão gasosa.

O índice de qualidade de água para proteção de comunidades aquáticas, considerando os níveis de nitrogênio amoniacal total, da bacia do rio Uberabinha, mostrou-se bom para os pontos 3 e 4, exceto para os pontos 1 e 2 onde deve ser feito um controle das fontes de poluição, para que valores deste parâmetro, nestes pontos do rio apresentem-se abaixo do limite máximo estabelecido na resolução CONAMA 357.

\section{Agradecimentos}

\section{Ao Instituto de Química da UFU e à FAPEMIG.}

\section{Referências}

1. Silva, G. S.; Jardim, W.F.; Quim. Nova, Vol. 29, (4), 689-694, 2006.

2. Environmental Protection Agency of United State (USEPA); Update of ambient water quality criteria for ammonia - EPA 822R-99-014, Washington, 1999.

3. Brion, N.; Billen, G.; Wat.Res., 34 (12), 3213-3221, 2000.

4. Regan, J.M.; Harrington, G.W.; Baribeau, h.; deleon, R. e Noguera, D.N.; Water Res., 37, 197-205, 2003.

5. Batalha, B.H.L. \& Parlatore, A.C.; CETESB, 1993.

6. Silva, G. S.; Tese de Doutorado, Universidade Estadual de Campinas, Brasil, 2004.

7. Comitê das Bacias Hídricas dos Rios Piracicaba, Capivari e Jundiaí; Relatório Zero, Piracicaba, 2000.

8. Conselho Nacional de Meio Ambiente (CONAMA); Resolução no 357 de 15 de março de 2005. Brasília, DF, 2005.

9. Bremner, J. M.; American Society of Agronomy Inc.: Publisher USA, p. 1149-1178, 1965.

10. Keeney, D. R.; Bremner, J. M.; Soil Sci., 104, 358, 1967.

11. Standard Methods for Examination of Water and Wastewater; 20th ed., American Public Health Association: Washington, 4-99 e 4-1241, 1998.

12. Yasuhara, T.; Nokihara, K.; J. Agric. Food Chem., 49, 4581, 2001.

13. Faria, L.C.; Pasquini, C. Anal. Chim. Acta.; 245, 183-190, 1991.

14. Reis, B.F.; Krug, F.J.; Vieira, J.A.; Giné, M.F.; J. Braz. Chem. Soc.; 8, 523-528, 1997.

15. Searle, P.L. The Analyst, 109, p.549-568, 1984.

16. VanStaden,J.F.;Taljaard,R.E.;Anal.Chim.Acta.;344,281-289,1997. 
17. Baccan, N; Andrade, J.C.; Godinho, O.E.S.; Barone, J.S.; Química Analítica Quantitativa Elementar; $3^{\text {a }}$ edição. Editora Edagard Blücher Ltda: São Paulo, 2001.

18. Miranda, C.E.S.; Reis, B.F. e Baccan, N.; Quím. Nova, 19, 623, 1996.

19. Olsen S.; Pessenda, L.C.R.; Ruzicka, J.; Hansen, E.H.; Analyst, 108, 905, 1981.

20. Araújo, C.S. T.; Carvalho, J. L.; Mota D. R.; Araújo,C.L.; Coelho, N.M.M.; Food chem. 92, 765-770, 2005.

21. Harris, D. C.; Análise Química Quantitativa, 5ª ed. LTC Ed.: Rio de Janeiro, 2001.

22. Skoog, D.A.; West, D.M.; Holler, F.J.; Fundamentals of Analytical Chemistry, 6a ed., Saunders College Pub.: Fort Worth, 1992.
23. Atkins, P.W.; Físico-Química, 6a ed., LTC- Livros Técnicos e Científicos Ed. S.A. ; Rio de Janeiro, 1999.

24. Espenson, J.; Chemicol Kinetics and Reaction Mechanisms. McGraw-Hill Book Co.: New York, 1981.

\section{Edmar I. Melo, Nívia M. M. Coelho \& Danilo A. Giarola.}

Universidade Federal de Uberlândia, CEP 38400.902, Uberlândia/MG *e-mail: edmarisaias@yahoo.com.br 